\title{
Mechanism and function of the outer membrane channel TolC in multidrug resistance and physiology of enterobacteria
}

\section{Helen I. Zgurskaya*, Ganesh Krishnamoorthy, Abigail Ntreh and Shuo Lu}

Department of Chemistry and Biochemistry, University of Oklahoma, Norman, OK, USA

\section{Edited by:}

Kunihiko Nishino, Osaka University, Japan

Reviewed by:

Rajeev Misra, Arizona State

University, USA

Herbert P. Schweizer, Colorado State

University, USA

*Correspondence:

Helen I. Zgurskaya, Department of Chemistry and Biochemistry,

University of Oklahoma, 101

Stephenson Parkway, Norman, OK

73019, USA.

e-mail: elenaz@ou.edu
TolC is an archetypal member of the outer membrane efflux protein (OEP) family. These proteins are involved in export of small molecules and toxins across the outer membrane of Gram-negative bacteria. Genomes of some bacteria such as Pseudomonas species contain multiple copies of OEPs. In contrast, enterobacteria contain a single tolC gene, the product of which functions with multiple transporters. Inactivation of tolC has a major impact on enterobacterial physiology and virulence. Recent studies suggest that the role of TolC in physiology of enterobacteria is very broad and affects almost all aspects of cell adaptation to adverse environments. We review the current state of understanding TolC structure and present an integrated view of TolC function in enterobacteria. We propose that seemingly unrelated phenotypes of to/C mutants are linked together by a single most common condition - an oxidative damage to membranes.

Keywords: multidrug efflux, outer membrane permeability, acid tolerance, enterobacterial virulence, oxidative stress

\section{DIVERSITY AND DISTRIBUTION OF TOIC-LIKE CHANNELS IN GRAM-NEGATIVE BACTERIA}

The important role of TolC in the structure and function of the outer membrane of $E$. coli is known for at least 30 years (Morona and Reeves, 1981, 1982; Morona et al., 1983). The early observations that tolC mutants are tolerant to colicin $\mathrm{E} 1$ and at the same time hypersensitive to certain dyes, drugs and detergents led to the conclusion that these mutants have alterations in the cell membrane. Later studies established that TolC and its homologs in other Gram-negative bacteria enable transport of various toxic molecules across the outer membrane (Benz et al., 1993; Fralick, 1996).

TolC belongs to the outer membrane efflux proteins (OEP) family (or "Outer Membrane Factor" family), members of which function in conjunction with three types of transport systems: ATP-binding cassette (ABC)-type, resistance nodulation division (RND)-type, and major facilitator superfamily (MF-type; Paulsen et al., 1997). The association between transporters and OEPs is mediated by periplasmic proteins named membrane fusion proteins (MFPs; Dinh et al., 1994; Zgurskaya et al., 2009). A structural model depicting a proposed arrangement of OEPs with the inner membrane permeases and periplasmic MFPs using the example of AcrAB-TolC is shown on Figure 1. The characteristic feature of this model is that TolC and other OEPs span the outer membrane and protrude deep into the periplasm.

Sequence analyses of OEPs showed that they are highly divergent with only two subtle common motifs (Johnson and Church, 1999). These motifs belong to the structural signature of OEPs their coiled-coil regions (Figure 2; Koronakis et al., 2000). The characterized OEPs cluster into three clades corresponding to their broadly defined efflux functions: (i) the multidrug efflux, where the best characterized representative is Pseudomonas aeruginosa OprM, (ii) the cation efflux with E. coli CusC as a typical representative, and (iii) the protein export (type I secretion system) represented by E. coli TolC (Hatfaludi et al., 2008). Perhaps as a result of such functional specialization, genomes of Gram-negative bacteria usually contain several OEP genes.

Four OEPs were identified in E. coli genome: tolC, yjcP ( $m d t P)$, yoh $G(m d t Q)$, and $y l c B$ (cusC; Sulavik et al., 2001). Inactivation of tolC leads to significant increase in susceptibility to multiple anti-bacterial agents suggesting that $\mathrm{TolC}$ is the major conduit for multidrug efflux across the outer membrane of E. coli (Fralick and Burns-Keliher, 1994; Sulavik et al., 2001). In addition, tolC is required for export of plasmid-encoded and chromosomal toxins such as hemolysin, colicin $\mathrm{V}$, and microcins (Wandersman and Delepelaire, 1990; Hwang et al., 1997; Delgado et al., 1999). Deletions of $y j c P$ and $y o h G$ did not affect the intrinsic levels of antibiotic resistance but cells lacking these genes were slightly more susceptible to puromycin, an antibiotic inhibiting protein translation (Sulavik et al., 2001). CusC is produced in a single operon with cusBA genes and is implicated in resistance against $\mathrm{Cu}(\mathrm{I}) / \mathrm{Ag}(\mathrm{I})$ ions generated under anaerobic conditions (Franke et al., 2003).

In comparison, $P$. aeruginosa (Pae) genome contains 18 OEPs (Jo et al., 2003). Phylogenetic analyses revealed that these OEPs could be subdivided into two subfamilies: the OprM subfamily comprising 11 highly homologous channels involved in multidrug efflux and the more divergent AprF protein export subfamily, which also includes OpmH and OpmM. The type I secretion protein AprF and OpmH are the most closely related to E. coli TolC. However, it is the OprM channel, which is constitutively expressed and confers the intrinsic resistance of $P$. aeruginosa to a wide 


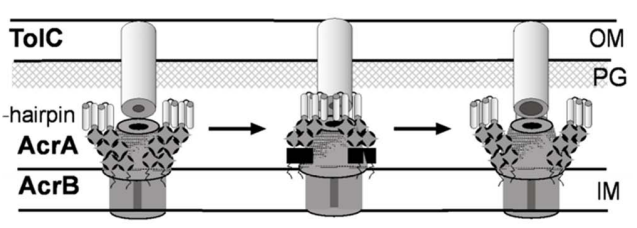

FIGURE 1 | A proposed mechanism of AcrAB-ToIC efflux pump (modified from Tikhonova et al., 2011). The tri-partite complex is assembled between the pre-assembled inner membrane (IM) complex AcrAB and the closed outer membrane (OM) channel TolC. Kinetic studies suggest that TolC binds directly to $\mathrm{Acr} B$ followed by engagement of AcrA. But an alternative order where AcrA binding to TolC precedes AcrB-TolC interaction cannot be excluded at this point. Docking of AcrA $\alpha$-hairpins onto TolC coiled-coil domain leads to conformational changes in the membrane proximal domain of AcrA, which are needed for stimulation of AcrB transport activity. The activated $A c r A B$ transporter triggers opening of the periplasmic tip of TolC to allow diffusion of substrates across the outer membrane. The open conformation of the complex is short-lived and relaxes into the closed state with or without dissociation of AcrA $\alpha$-hairpins from TolC.
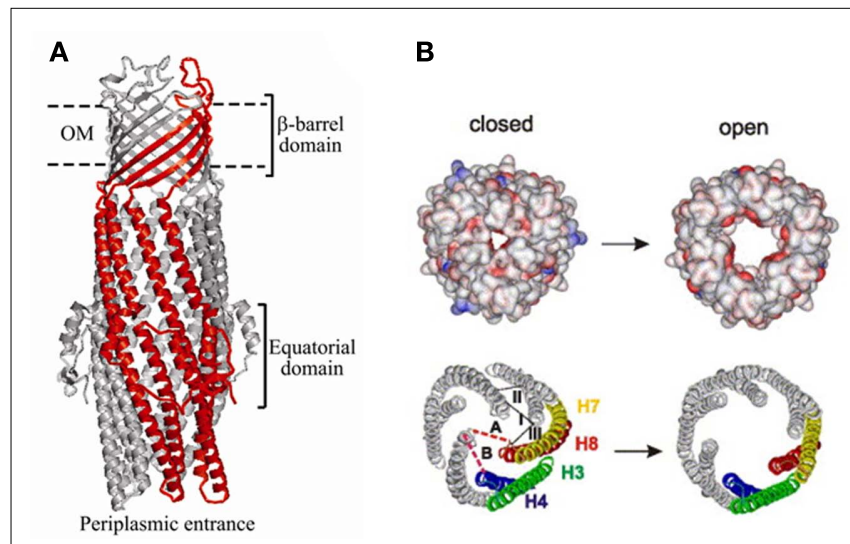

FIGURE 2 | Structure and mechanism of TolC. (A) Ribbon representation of TolC homotrimer (side view) with key domains indicated (reproduced from Zgurskaya et al., 2009 with permission from Elsevier). A monomer of ToIC is highlighted in red. (B) The proposed mechanism of TolC transition into the open state (reproduced from Koronakis, 2003 with permission from Elsevier). Space-filled (upper) and ribbon (lower) depictions of the closed and modeled open states of the tunnel entrance, viewed from the periplasm. The coiled-coils $\mathrm{H} 3 / \mathrm{H} 4$ and $\mathrm{H} 7 / \mathrm{H} 8$ of one protomer are colored and show the constraining intramonomer (I and II) and intermonomer (III) links.

spectrum of toxic compounds (Li et al., 1995). Mutational inactivation of other OEPs does not usually lead to dramatic changes in susceptibility (Chuanchuen et al., 2005). However, when overproduced in the absence of OprM, either OpmJ or OpmH confer resistance to a broad range of antimicrobials, complementing or even exceeding the spectrum of OprM (Jo et al., 2003). This and other studies suggested that division of OEPs based on substrate specificities is limited to their sequence homologies with most of OEPs able to transport a variety of substances across the outer membrane.

The ability to translocate a given substrate by an OEP depends on its versatility in association with transporters. TolC functions with the majority of MFP-dependent transporters encoded in the genome of E. coli, an exception is a cation transporter CusBA, which functions with CusC (Nishino and Yamaguchi, 2001). Similar requirements for TolC were described in Salmonella, Vibrio, Klebsiella, and others species (Bina and Mekalanos, 2001; Barabote et al., 2003; Gil et al., 2006; Cosme et al., 2008; Al-Karablieh et al., 2009; Fenosa et al., 2009; Ferhat et al., 2009; Horiyama et al., 2010). The multi-functionality is also reflected by the fact that the tolC gene in these organisms is transcribed independently from the inner membrane counterparts and its genetic context is conserved only in the closely related species (i.e., all Enterobacteriaceae).

On the other side of the OEP spectrum are specialized cation efflux and type I secretion OEPs that function exclusively with specific transporters. These OEPs are usually expressed in gene clusters along with the inner membrane components of the complex. However, even these specialized OEPs demonstrate certain promiscuity. For example, Serratia marcescens contains several type I secretion systems, which export such proteins as the lipase LipA, the metalloprotease PrtA, and the heme-binding protein HasA (Letoffe et al., 1993, 1994; Akatsuka et al., 1995). Studies of hybrid transporters demonstrated that OEPs do not possess any substrate specificity and their involvement in transport reactions is determined by their ability, or the lack of such, to bind an inner membrane complex. In general the substrate specificity of the complex appears to be determined by the inner membrane complex (Akatsuka et al., 1997).

\section{STRUCTURE, FOLDING, AND ASSEMBLY OF TOIC IN THE OUTER MEMBRANE}

The structure of TolC solved by Koronakis et al. (2000) was followed by high-resolution structures of CusC, P. aeruginosa OprM, and Vibrio cholerae VceC (Akama et al., 2004; Federici et al., 2005; Phan et al., 2010; Kulathila et al., 2011). Despite very low sequence similarity between these proteins, their structures are dramatically similar and unique among outer membrane proteins (OMPs; Andersen et al., 2001). Extending from the extracellular space well into the periplasm, TolC is a $140-\AA$ long, cannon-shaped protein made up of a 12 -stranded $\beta$-barrel, an $\alpha$-helical domain, and a mixed $\alpha / \beta$ equatorial domain (Figure 2A; Koronakis et al., 2000). The $\beta$-barrel of TolC is a trimer embedded into the outer membrane, where each protomer contributes only a third of the $\beta$-strands. In contrast, in a typical OMP each protomer is folded into a $\beta$-barrel (Delcour, 2002). The $\alpha$-domain is made up of two long helices, that span the nearly $100 \AA$ into the periplasm, and four shorter helices that stack up to make two long, pseudo-continuous helices spanning the length of the entire $\alpha$-domain as well. The dense packing of the three curved sets of coiled-coils has been proposed to keep the periplasmic opening of TolC in its "closed" conformation (Figure 2B). Still, the cavity of TolC is one of the largest known among protein structures, holding about 43,000 of solvent and it is capable of allowing passage of particles as large as $160 \mathrm{kDa}$ (Andersen et al., 2001).

The unique structure of TolC suggested that its folding and assembly into the outer membrane are likely also to be distinct from other OMPs (Werner et al., 2003). Two basic models are proposed for the OMP assembly. The most experimentally supported model postulates that nascent polypeptides of OMPs are deposited 
in their soluble state into the periplasm. In the alternative model, OMP polypeptides remain weakly associated with the inner membrane as they reach the outer membrane via membrane contact sites (reviewed in Hagan et al., 2011). TolC, like other proteins, is synthesized in the cytoplasm of E. coli and is transported across the inner membrane into the periplasm. Cytoplasmic chaperones of the Sec machinery target the cleavable N-terminal signal peptide of the protein and aid with its translocation. The cleavage of the signal peptide yields a mature, 471-amino acid TolC, which folds and assembles in the periplasm. Studies from Misra's group suggested that TolC, like other OMPs, emerges into the periplasm as a soluble intermediate sensitive to proteinase K (Werner et al., 2003). However, unlike other OMPs, the assembly of TolC trimers is independent from known periplasmic chaperones such as SurA, Skp, and DegP, as well as lipopolysaccharides. This finding implied that TolC either folds in a unique manner or uses unique factors. However, a signal sequence-less mature TolC folds and forms trimers even in the cytoplasm suggesting that no external factors are required (Masi et al., 2009). The large $\alpha$-helical coiled-coil domain likely enables the protein to stay in the soluble state without help from the periplasmic chaperones.

The final step in the assembly of TolC, its insertion into the outer membrane, remains largely unclear. In $E$. coli, assembly of $\beta$-barrel OMPs including TolC is facilitated by the five-protein BamABCDE complex. In this complex, BamA and BamD are essential for cell growth (reviewed in Hagan et al., 2011). The periplasmic portion of BamA comprising the five POTRA (polypeptide translocation associated) domains is shown to receive unfolded OMPs from periplasmic chaperones. In addition, POTRA domains serve as docking sites for the rest of Bam proteins. The trans-membrane $\beta$-barrel domain of BamA is believed to provide a scaffold during the final insertion of OMPs into the membrane. The role of BamD is less clear but it could assist BamA during the final steps of assembly of oligomeric OMPs or could facilitate dissociation of a folded OMP from BamA.

Since folding in the periplasm and translocation of TolC to the outer membrane do not require the known OMP chaperones, the engagement of TolC by BamA is expected to differ from other OMPs. Indeed, a recent study by Bennion et al. (2010) showed that TolC bypasses not only the requirement for chaperones but also the requirement for the first POTRA domain of BamA. Since assembly of TolC still requires functional BamA/BamD proteins, the OMPs and TolC pathways seem to merge at the later stages, perhaps during insertion into the membrane. The process of insertion and functional interactions that occur during assembly of OMPs and TolC however remain unknown.

\section{TRANSPORT MECHANISM OF TOIC}

The structure of TolC suggested a possible mechanism of transport. The large periplasmic extension of TolC channel is thought to be a docking site for MFPs and transporters. Since in crystals the periplasmic entrance of TolC and other OEPs is tightly closed so that even ions cannot easily diffuse through, the association with the inner membrane complex is thought to trigger opening of TolC channel (reviewed in Koronakis, 2003). This critical step in transport across the outer membrane however has not been yet successfully reconstituted in vitro. The proposed allosteric opening mechanism envisages that the inner coiled-coil $\alpha$-helices $(\mathrm{H} 7 / \mathrm{H} 8)$ undergo an iris-like movement to realign with the outer coils $(\mathrm{H} 3 / \mathrm{H} 4)$, thereby enlarging the pore in a "twist-to-open" transition (Figure 2B). This hypothesis is supported by studies of TolC mutants with disrupted network of constraining hydrogen bonds (Andersen et al., 2002). The intra-protomer bond Y362R367 tethers the inner coiled-coil $\mathrm{H} 7 / \mathrm{H} 8$ to the outer $\mathrm{H} 3 / \mathrm{H} 4$ coiled-coils. Substitutions in these residues increase the conductance of TolC channel from the "closed" $80 \mathrm{pS}$ to partially open 205-370 pS (R367S mutant) and maximum conductance of 800$1000 \mathrm{pS}$ in the double R367S Y362F TolC mutant ( TolC $^{\mathrm{YFRS}}$ ). The sequential open states were also found in crystal structures of these TolC mutants supporting further the idea that destabilization of ionic bonds in the periplasmic tip could dilate the TolC pore and allow passage of substrates through the channel (Bavro et al., 2008; Pei et al., 2011).

These studies raised several questions about the mechanism of TolC. From the description above it is obvious that significant conformational changes in TolC are needed to undergo transition into the open state. Whether association with the inner membrane complex is sufficient to trigger such transition is unclear. The best currently available model of AcrAB-TolC complex postulates TolC interactions with both AcrA and AcrB proteins (Symmons et al., 2009). Detailed discussions of the assembly and mechanism of AcrAB-TolC can be found in several recent review articles (Misra and Bavro, 2009; Nikaido and Takatsuka, 2009; Pos, 2009; Zgurskaya, 2009). The latest data indicate that AcrA and AcrB exist in the inner membrane as a preformed complex and remain associated with each other during TolC docking (Figure 1). It appears that TolC can bind AcrB directly and that the tri-partite complex is formed between AcrA and TolC engaged by AcrB (Tikhonova et al., 2011). It is unclear however whether the same order of interactions could be achieved in assembly of TolC-dependent transporters belonging to $\mathrm{ABC}$ and MF families. Transporters of these two families lack the sizable periplasmic domains of AcrB and therefore are unlikely to bind TolC directly. In such complexes, MFPs are thought to play the major role in both recruitment and opening TolC.

Once the complex is assembled, all three export components undergo conformational changes, which presumably lead to the opening of TolC and extrusion of substrates (Symmons et al., 2009). An extensive amount of research has been carried out to reveal specific residues and regions important for the functional interactions between TolC and the inner membrane complexes (Stegmeier et al., 2006; Lobedanz et al., 2007; Krishnamoorthy et al., 2008). Several independent studies converged onto a model, in which MFPs bind TolC in stoichiometry six MFP to three TolC (Tikhonova et al., 2009, 2011; Janganan et al., 2011; Su et al., 2011; Xu et al., 2011a). The $\alpha$-helical hairpins of MFPs play a critical role in the assembly of the complex by docking onto the intra- and inter-protomer grooves of TolC and forming a sheath-like structure surrounding the periplasmic tip of TolC (Figures 1 and 3A). This model was recently challenged by findings that MFPs could also interact with TolC in a tip-to-tip manner (Xu et al., 2011b). In the latter case, MFPs extend the periplasmic tunnel-like structure of TolC all the way into the inner membrane (Figure 3B). It is presently unclear whether a tip-to-tip MFP-TolC complex is an 

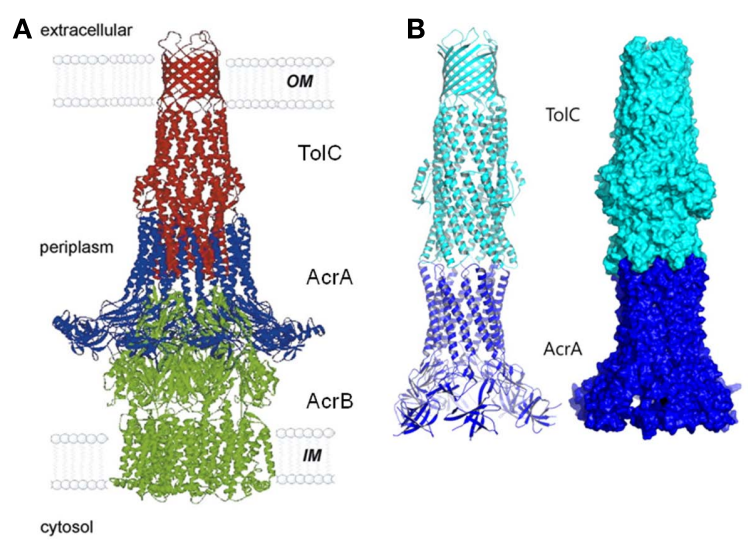

FIGURE 3 |The modeled structure of AcrAB-ToIC complex. Two alternative interfaces between components of the complex are supported by experimental data. In the first model (A), AcrA $\alpha$-hairpins dock into the inter-and intra-protomer grooves of TolC coiled-coil domain and TolC directly binds AcrB (reproduced from Eswaran et al., 2004 with permission from Elsevier). In the alternative model (B), AcrA and TolC interact with each other in a tip-to-tip manner, which would separate AcrB and TolC and increase the inter-membrane length of the complex by about $40 \AA$ (Xu et al., 2011a). A similar interaction was also proposed between MacA and TolC (reproduced from Xu et al., 2010 with permission from Elsevier).

intermediate step during the assembly or is in fact, the only mode of interaction between the two proteins.

It is clear however, that binding to TolC changes the conformation of a MFP. CvaA, a MFP functioning with TolC in export of colicin V, is highly unstable and rapidly cleaved by periplasmic proteases in cells lacking TolC (Hwang et al., 1997). Similar changes in sensitivity to proteases were reported for the hemolysin exporting HlyD (Thanabalu et al., 1998), multidrug efflux AcrA, and macrolide efflux MacA (Ge et al., 2009; Modali and Zgurskaya, 2011). In the case of AcrA and MacA, we demonstrated that these conformational changes affect the membrane proximal domain of the protein, which directly interfaces with the transporter (Figure 1; Modali and Zgurskaya, 2011; Tikhonova et al., 2011). We also proposed that TolC-dependent conformational change in the membrane proximal domain of MFP may be required for the complex assembly and activation of the transporter (Modali and Zgurskaya, 2011; Tikhonova et al., 2011).

The dramatic structural differences between RND, ABC, and MF transporters imply that these transporters either do not have any direct contact with TolC or that there is certain flexibility in how TolC is engaged into complexes. AcrB and other RND pumps are likely to directly bind TolC and contribute to TolC opening (Tamura et al., 2005; Bavro et al., 2008; Tikhonova et al., 2011). This model is also compatible with structural features of RND pumps such as the threefold symmetry and large periplasmic domains matching the geometry of TolC periplasmic tip (Murakami et al., 2002; Pos, 2009). In contrast, very little structural information is available for $\mathrm{ABC}$ and MF pumps and the current assumptions are based on what we know about their TolC-independent homologs. For the macrolide efflux ABC-type MacB and its close homologs, direct interaction with TolC is still a possibility because these transporters also possess large periplasmic domains with structural features reminiscent of those of AcrB (Xu et al., 2009). However, the type I secretion $\mathrm{ABC}$ transporters and MF transporters seem to be unable to reach the periplasmic tip of TolC. Therefore, in these complexes TolC opening is achieved exclusively through the action of MFPs. Molecular details of such mechanism remain unknown.

It is also unknown how conformational transitions in TolC are integrated into reaction cycles. One possibility is that the assembly of the trans-membrane complex stabilizes the open conformation of TolC, so that the life-time of the complex and the turnover number of the transporter determine the number of substrate molecules translocated through TolC. In the type I secretion systems, binding of substrate to the inner membrane complex seems to trigger TolC recruitment and stabilization of its open state (Thanabalu et al., 1998). However, TolC forms more stable complexes with drug efflux transporters, which are independent of the presence of substrates (Tikhonova and Zgurskaya, 2004).

Furthermore, kinetic analyses showed that mutational opening of TolC decreases its affinity to AcrAB suggesting that TolC opening could actually trigger the disassembly of the complex (Tikhonova et al., 2011). Such mechanism could explain how the low permeability barrier of the outer membrane is maintained during efflux. It is apparent that the open TolC channel would be a significant breech of the outer membrane permeability barrier. Studies of vancomycin resistance in E. coli show that cells containing functional AcrAB-TolC pump are more susceptible to this antibiotic than cells lacking either AcrAB or TolC (Bavro et al., 2008 and unpublished data). Since vancomycin is too large to cross the outer membrane by diffusion, the explanation for this result is that this antibiotic can slip through TolC engaged by AcrAB. One could imagine that to limit the influx of substrates through TolC, the complex is assembled with the closed TolC conformer and that the transition into the open state is triggered, for example, by substrate binding, as proposed for CusBAC (Kim et al., 2011). In the open state the complex is unstable and rapidly dissociates relaxing TolC into its closed conformation (Figure 1).

In summary, the current models of TolC function in transport across the outer membrane involve opening of the periplasmic entrance of TolC upon association with an inner membrane complex. Despite the structural and functional diversity of inner membrane complexes that depend on TolC for their activities, it is likely that the same set of chemical bonds must be rearranged during the switch of TolC into the open state. However, depending on the transporter, the amino acid residues that participate in this bonding and stabilize the open TolC conformation could belong either to an inner membrane transporter, an MFP or both. How long TolC stays in the open conformation will define the efficiency of transport across the outer membrane. The fast disengagement of TolC upon transition into the open state could be important to maintain the permeability barrier of the outer membrane.

\section{REGULATION OF TOIC EXPRESSION}

Although E. coli tolC gene is constitutively expressed at $\sim 1500$ protein copies per cell (Tikhonova and Zgurskaya, 2004), its 
expression is further upregulated in response to at least six different environmental signals. tolC is a member of the marA/soxS/rob, PhoPQ, BaeSR, and EvgAS regulons that promote resistance to multiple antibiotics, to superoxides and are required for survival under acidic conditions, extracytoplasmic stress, and during infections (Aono et al., 1998; Eguchi et al., 2003; Nishino et al., 2005; Zhang et al., 2008). Four tolC promoters act to tune up TolC levels to specific conditions (Zhang et al., 2008). The p1 promoter has significant constitutive expression under laboratory conditions and is responsive to none of the above regulators. The $\mathrm{p} 2$ promoter is responsive to EvgAS and PhoPQ but not the others. The p3 and p4 promoters are activated by MarA, SoxS, and Rob, with each activator being regulated by different environmental signals. There is no a BaeR-binding motif upstream of tolC suggesting that the effect of BaeR overproduction on upregulation of tolC could be indirect (Nishino et al., 2005).

The environmental signal for EvgAS is not known but this regulator activates expression of multidrug efflux pumps and genes required for survival at low pH (Masuda and Church, 2003). BaeRS responds to indole, ethanol, EDTA, flavonoids, and sodium tungstate (Bury-Moné et al., 2009; Leblanc et al., 2011). PhoPQ is activated by low $\mathrm{pH}$ and low $\mathrm{Mg} 2+$ concentrations, conditions that exist in phagosomes (Groisman, 2001). Genes marA and soxS are paralogs, transcription of which is activated by treating cells with salicylate and paraquat, respectively, and the activity of Rob can be increased post-transcriptionally by treatment with $2,2^{\prime}$ Dipyridyl, bile salts and decanoate (Martin and Rosner, 2002). In addition, MarA and SoxS transcription as well as Rob activity are upregulated in tolC mutants (Rosner and Martin, 2009). These multiple transcriptional regulatory elements possibly tailor a particular TolC function (efflux, protein secretion, acid resistance) to different environments and by this means promote cellular adaptation and proliferation (Figure 4; Zhang et al., 2008). Regulation of tolC in S. Typhimurium is similar to that in E. coli and involves global regulators marA/soxS/rob as well as a transcriptional regulator RamA (Randall and Woodward, 2002; Nishino et al., 2006; Webber et al., 2009).

\section{ROLE OF TOIC IN ENTEROBACTERIAL PHYSIOLOGY}

It is well established that mutants lacking tolC have pleiotropic phenotypes including increased susceptibility to antibiotics, cell division defects, changes in the expression of outer membrane porins, sensitivity to acid, decreased virulence, and others (see below). At least some of these phenotypes could be explained by the fact that deletion of tolC leads to upregulation of marA and soxS transcription and Rob activity (Rosner and Martin, 2009). For example, tolC mutants contain very low levels of OmpF porin, which is downregulated via micF RNA activation by Rob (Morona and Reeves, 1982; Misra and Reeves, 1987; Chubiz and Rao, 2011). Other phenotypes are likely to arise because of the extensive functional interactions involving TolC either directly or indirectly (Figure 4).

\section{ANTIBIOTIC RESISTANCE}

Inactivation of tolC increases susceptibility of enteric bacteria to an extremely broad spectrum of antimicrobial agents including

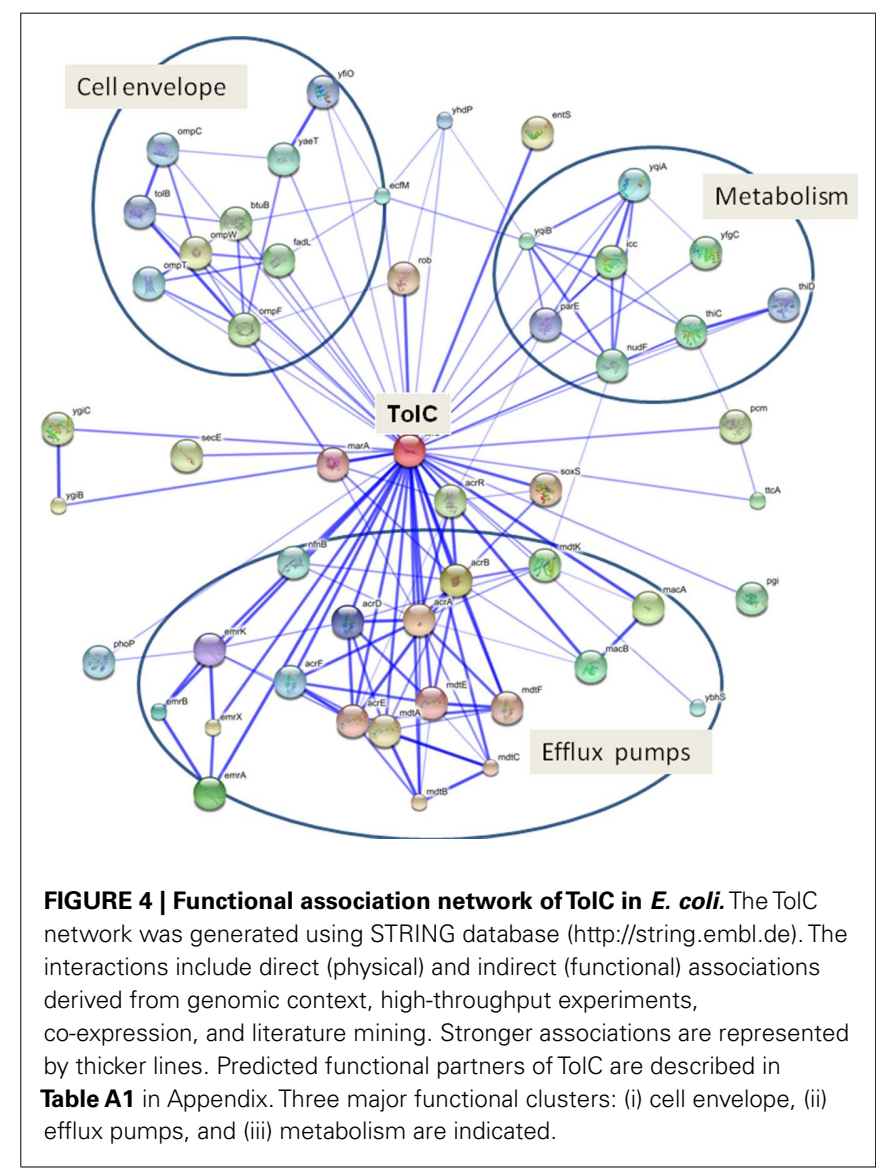

antibiotics, detergents, dyes, organic solvents, and others (Sulavik et al., 2001). This function of TolC is dependent on the activity of efflux pumps. Usually bacteria express at least one "housekeeping" efflux pump such as AcrAB in E. coli, which in association with TolC reduces periplasmic concentrations of antibiotics (Nikaido, 2009). Drug susceptibilities of $\triangle a c r A B$ and $\triangle$ tolC strains are similar but not identical with the more severe phenotype in cells lacking tolC (Sulavik et al., 2001). This difference could be attributed to TolC association with other efflux pumps. However, besides $a c r A B$, none of the confirmed or putative multidrug efflux pumps were found to contribute to the intrinsic resistance. Therefore, other functions of TolC could be reflected in the increased susceptibility of E. coli to antimicrobials as well. In another survey of more than 10,000 phenotypes, the phenotypes of tolC and $a c r B$ mutants correlated with each other $(r=0.78)$ confirming the functional link between these genes (Nichols et al., 2011).

Increased efflux pump expression has been documented in association with resistance to several antibiotic classes (reviewed in references Poole, 2004; Piddock, 2006). Only AcrAB-TolC overproduction, however, has been shown to contribute to clinical antibiotic resistance in E. coli and Salmonella species. Surprisingly, no significant correlation was found between overproduction of $a c r A B$ and tolC. In one of the most recent study (Swick et al., 2011), among 37 fluoroquinolone-resistant clinical isolates of E. coli, 22 overexpressed $a c r A$ and 25 overexpressed $a c r B$ more 
than 2 SD above the respective means for the fluoroquinolonesusceptible isolates. In contrast, only three fluoroquinoloneresistant isolates overexpressed tolC by approximately sevenfold. Overall, the average tolC expression levels of the fluoroquinolonesusceptible and fluoroquinolone-resistant clinical isolates did not differ statistically. tolC did not correlate with either $a c r A$ or $a c r B$ and it does not appear that tolC is overexpressed with $\operatorname{acr} A B$ for acquisition of fluoroquinolone resistance despite the ability of all three genes to respond to MarA regulation (Barbosa and Levy, 2000). This result indicates that (i) there are significant regulation differences between tolC and $a c r A B$ operons and (ii) amounts of TolC do not limit the drug efflux capacity of cells.

\section{EXPULSION OF METABOLITES}

Recent studies established that the intra- and extra-cellular concentrations of several metabolites are affected by tolC. Hantke et al. (2011) showed that $\Delta$ tolC cells require significantly lower concentrations of cAMP to induce expression of catabolic enzymes. Since $\sim 90 \%$ of cAMP produced by intracellular adenylate cyclases is found in the culture medium, authors propose that TolC is involved in export of cAMP. However, no transporter was identified that could export cAMP through TolC leaving open the question whether changes in CAMP concentrations are due to export function of TolC or due to changes in the metabolic state of the cells.

Similar observations were reported for porphyrins and cysteine, which when produced in excess, are toxic to cells and expelled into the culture medium (Tatsumi and Wachi, 2008). Porphyrin is a constituent of the heme and is a cofactor for cytochromes that participates in oxidative phosphorylation (Zufferey et al., 1997). When added exogenously, the precursor of porphyrin, D-amino levulinic acid (ALA) stimulates porphyrin biosynthesis in both the wild-type and tolC mutant cells. However, the tolC mutant grown in the presence of ALA had accumulated a larger amount of porphyrin(ogen)s intracellularly, while the wild-type cells excreted porphyrins into the medium (Tatsumi and Wachi, 2008). Authors proposed that ALA incorporated into the cells was metabolized to porphyrin(ogen)s, and the excess porphyrin(ogen)s were exported by the TolC-dependent efflux system. Screening of mutants lacking all known TolC-dependent pumps did not identify a transporter involved in porphyrin efflux.

Presence of high levels of cysteine is toxic to cells as it promotes oxidative DNA damage by driving Fenton reaction (Park and Imlay, 2003) and also by inhibiting enzymes in the cysteine biosynthetic pathway. In cysteine overproducers, TolC is important for alleviation of the cysteine stress by presumably exporting it out of the cell (Wiriyathanawudhiwong et al., 2009). As in the case with porphyrins, no efflux pumps that partner with TolC to excrete cysteine were identified. tolC mutants are also hypersensitive to exogenous glutathione in the efflux independent manner (Dhamdhere et al., 2010).

In addition, E. coli TolC was implicated in export of siderophores that are required in iron acquisition (Bleuel et al., 2005; Newton et al., 2010). Acquisition of iron in response to its scarcity inside the cell has been attributed to enterobactin, which is secreted into the medium and after sequestering iron transported back into the cell as ferric-enterobactin. Deletion of tolC resulted in the total loss of enterobactin export and iron acquisition.

\section{ACID TOLERANCE}

Several pieces of evidence link tolC expression to acid $\mathrm{pH}$ resistance. E. coli, when challenged with very low $\mathrm{pH}$ responds by the induction of the acid resistance factor, glutamate decarboxylase gene $(\operatorname{gad} A B)$ expression (reviewed in Foster, 2004). The deletion of tolC made the cells susceptible to acidic environment (Deininger et al., 2011). EmrB and MdtB efflux pumps seem to function with TolC to enable $E$. coli survival at extreme acidic $\mathrm{pH}$. However, tolC mutant, but not emrB or $m d t B$, lacked the expression of GadAB system and was impaired when grown in medium at $\mathrm{pH} 6.0$ or below. These findings suggested that requirement for tolC in acid tolerance is not limited to its functions with EmrB and MdtB (Deininger et al., 2011).

Consistent with its role in acid tolerance and being a member of the EvgA acid resistance regulon, TolC shows acid-enhanced expression in the E. coli proteome (Yohannes et al., 2004). Interestingly, in F. tularensis, the tolC homolog is even expressed in the same operon with gad (Gil et al., 2006). Assembly of TolC into efflux complexes is stimulated by acidic $\mathrm{pH}$ suggesting that the acid-dependent expression and MDR assembly could explain the increased sensitivity of bacteria to many antibiotics above $\mathrm{pH}$ 7 (Tikhonova et al., 2009). It seems that both the export and the regulatory functions of $\mathrm{TolC}$ are fully engaged under acidic conditions.

\section{CELL MEMBRANE INTEGRITY}

Studies from this lab showed that the loss of TolC leads to metabolic shutdown and growth defects of E. coli grown in a minimal medium with glucose. We found that the cytoplasmic membrane stress, depletion of essential metabolites, and alteration in $\mathrm{NAD}^{+} / \mathrm{NADH}$ ratios are the reasons for the TolC-dependent growth impairment (Dhamdhere and Zgurskaya, 2010). The tolC phenotype was partially rescued by YgiBC and YjfMC, which have parallel functions independent from TolC. Surprisingly, the deletion of tolC triggered activation of the Psp regulon, which responds to the dissipation of proton motive force by favoring anaerobic respiration of nitrate (Bury-Moné et al., 2009). The transcriptional regulator PspF derepresses a number of genes including the tolpal trans-envelope complex, which is required to maintain cell envelope integrity, regulator $h y f R$ controlling expression of genes responsible for the proton-translocating formate dehydrogenase system and formate reductase and nor $W$, which encodes a flavoreductase important for nitric oxide reduction (Bury-Moné et al., 2009). Activation of Psp regulon strongly suggests that under conditions of aerobic growth in the presence of glucose, deletion of tolC compromises the integrity of the inner membrane leading to inactivation of $\mathrm{NADH}$ oxidases, and dissipation of proton motive force (Dhamdhere and Zgurskaya, 2010). These results also suggest that upregulation of SoxS, MarA, and Rob pathways in tolC mutants (Rosner and Martin, 2009) could be directly in response to the membrane stress and metabolic imbalance.

\section{VIRULENCE AND PATHOGENESIS}

Apart from its role in multidrug resistance and physiology, TolC and its homologs have been implicated in the virulence 
and pathogenesis of enteropathogenic E. coli, Salmonella, Vibrio, Haemophilus, Francisella, Legionella, and other species (Stone and Miller, 1995; Bina and Mekalanos, 2001; Barabote et al., 2003; Trepod and Mott, 2004; van Amsterdam et al., 2005; Gil et al., 2006; Nishino et al., 2006; Posadas et al., 2007; Reddy et al., 2007; Cosme et al., 2008; Ferhat et al., 2009). Since during establishment and propagation of infection, bacteria encounter multiple stresses and challenges, the protective function of TolC in multidrug efflux, acid tolerance, and membrane integrity plays an important role. In addition, as a part of type I secretion system, TolC is directly involved in delivery of various virulence factors. Among characterized substrates of the type I systems are RTX toxins such as E. coli $\alpha$-hemolysin, extracellular enzymes (protease, lipases, glycanases) as well as surface proteins (S-layer proteins; Akatsuka et al., 1997; Delepelaire, 1998). These systems can be divided into two subtypes based on the $\mathrm{N}$-terminal vs. the C-terminal location of the secretion signal of the substrate (Delepelaire, 2004). However, the mechanism of transport seems to be similar for all type I secretion systems.

Perhaps the best studied type I system is E. coli HlyBD-TolC exporting $\alpha$-hemolysin. Encoded by hlyA gene, $\alpha$-hemolysin is $110 \mathrm{kDa}$ protein that exhibits cytolytic activity. It is expressed as a pro-toxin and then converted into a cytolytic form by HlyC, an acyltransferase (Trent et al., 1998). Once inside the host, hemolysin cause lysis of red blood cells and release heme, which is a rich source of iron for E. coli. Except for tolC, the hlyCABD genes are arranged together in the same operon, where $h l y B$ encodes an inner membrane ABC-type transporter and $h l y D$ encodes a MFP. TolC is recruited into the complex only when $\alpha$-hemolysin is already bound to HlyBD.

Screening of TolC mutants identified specific amino acid residues that are important for secretion of $\alpha$-hemolysin but not for efflux of antibiotics (Vakharia et al., 2001). Surprisingly, TolC mutants T140A and S257P secreted an enzymatically inactive hemolysin suggesting that TolC not only provides a channel for hemolysin to cross the outer membrane but also contributes to the proper folding of the secreted protein.

Secretion of heat stable enterotoxins I (STI) and II (STII), which cause diarrhea in hosts infected with the enterotoxigenic E. coli, also requires TolC but the mechanism differs from that of the type I system (Burgess et al., 1978; Aimoto et al., 1982). Both STI and STII are synthesized as pre-proteins (Okamoto and Takahara, 1990). Once the pre-ST toxins reach the periplasm through the Sec machinery, the N-terminal signal sequence is cleaved to give the pro-ST toxin (Okamoto and Takahara, 1990). Further, the toxin is modified in the periplasm to a form that can be secreted into the extracellular space (Yamanaka et al., 1993). The role of TolC in the ST export from the periplasm and across the outer membrane has been established in earlier studies (Foreman et al., 1995; Yamanaka et al., 1998) but the inner membrane complex that enables this TolC function remained unknown until recently. It appears that the macrolide efflux pump MacAB associates with TolC in the secretion of enterotoxin STII but not STI (Yamanaka et al., 2008). How the fully folded STII is secreted from the periplasm by MacAB-TolC remains unclear.
Given the crucial role of TolC in secretion and cell protection, it is not surprising that tolC mutants are attenuated in infection models. Stone and Miller (1995) showed that S. enteridis TolC is required for virulence in murine infection model. $S$. Typhimurium ability to invade and persist in mouse monocyte macrophages, embryonic cells and colonization of chickens were similarly affected when tolC was deleted from its chromosome (Buckley et al., 2006). The authors proposed that the deletion of tolC probably affected the ability of Salmonella to export host antimicrobials in conjunction with AcrAB proteins. Webber et al. (2009) demonstrated that AcrA, AcrB, and TolC are each required for efficient adhesion to and invasion of epithelial cells and macrophages by Salmonella in vitro. Gene expression profiles showed that this phenotype is a result of decreased expression of numerous genes encoding proteins involved in pathogenicity including chemotaxis and motility genes and 14 Salmonella pathogenicity island (SPI)-1-encoded type III secretion system genes, including sopE, and associated effector proteins. Enteroaggregative E. coli (EAEC) adheres to the intestinal mucosa forming a biofilm and secretes toxins that causes severe diarrhea in the host. Recently, it was shown that TolC deletion can prevent biofilm formation and aggregation of EAEC due to decreased hydrophobicity of the bacterial surface suggesting the role of TolC in cell-cell adhesion in aqueous medium and also in the reduced levels of fimbriae proteins (Imuta et al., 2008).

\section{INTEGRATED VIEW OF TOIC FUNCTION IN ENTEROBACTERIA: A HYPOTHESIS}

There is no doubt that inactivation of TolC impairs the cellular capacity for detoxification and repair. However, it seems unlikely that TolC is directly involved in export of metabolites, for which no MFP-dependent efflux pump could be identified. Given an extensive functional network of TolC (Figure 4), multiple factors could lead to observed changes in enterobacterial physiology. However, the described above seemingly unrelated phenotypes are linked together by a single most common condition - an oxidative damage to membranes (Imlay, 2008). (i) Growth defects of tolC mutants are exaggerated by the aerobic glucose metabolism, low $\mathrm{pH}$, and starvation, the conditions generating the oxidative stress. (ii) The activity of NADH oxidases, like NDH-I, is decreased in tolC $\mathrm{C}^{-}$cells leading to increased concentrations of NADH. Inhibition of NADH oxidases and accumulation of NADH induces formation of reactive oxygen species responsible for oxidative stress. (iii) Oxidative damage in tolC mutants provides an explanation for activation of marA/SoxS/rob and Psp responses in these cells. (iv) Depletion of a proton motive force and the metabolic shutdown increase the intracellular concentration of cAMP, which cannot be exported because transport reactions are halted as well. It is likely that activity of many secondary transporters is compromised in tolC mutants leading to accumulation of intermediate metabolites. (v) Porphyrins and cysteine, the two known metabolites affected by TolC, cause oxidative stress in the presence of $\mathrm{Fe}^{2+}$ ions. Accumulation of either one in tolC mutant could further contribute to the stress. (vi) TolC is the major factor in protection against bactericidal and redox-active antibiotics that not only inhibit specific targets but also kill cells by generating reactive oxygen species and damaging membranes (Kohanski et al., 2007). 
Finally, during infection the major challenge presented to bacterial cells are reactive oxygen species. tolC mutants already defective in detoxification are further compromised by inability to deal with oxidative stress, which could be an additional factor contributing to attenuation.

\section{REFERENCES}

Aimoto, S., Takao, T., Shimonishi, Y., Hara, S., Takeda, T., Takeda, Y., and Miwatani, T. (1982). Amino-acid sequence of a heat-stable enterotoxin produced by human enterotoxigenic Escherichia coli. Eur. J. Biochem. 129, 257-263.

Akama, H., Kanemaki, M., Yoshimura, M., Tsukihara, T., Kashiwagi, T., Yoneyama, H., Narita, S., Nakagawa, A., and Nakae, T. (2004). Crystal structure of the drug discharge outer membrane protein, OprM, of Pseudomonas aeruginosa: dual modes of membrane anchoring and occluded cavity end. J. Biol. Chem. 279, 52816-52819.

Akatsuka, H., Binet, R., Kawai, E., Wandersman, C., and Omori, K. (1997). Lipase secretion by bacterial hybrid ATP-binding cassette exporters: molecular recognition of the LipBCD, PrtDEF, and HasDEF exporters. J. Bacteriol. 179, 4754-4760.

Akatsuka, H., Kawai, E., Omori, K., and Shibatani, T. (1995). The three genes lipB, lipC, and lipD involved in the extracellular secretion of the Serratia marcescens lipase which lacks an $\mathrm{N}$-terminal signal peptide. J. Bacteriol. 177, 6381-6389.

Al-Karablieh, N., Weingart, H., and Ullrich, M. S. (2009). The outer membrane protein $\mathrm{TolC}$ is required for phytoalexin resistance and virulence of the fire blight pathogen Erwinia amylovora. Microb. Biotechnol. 2, 465-475.

Andersen, C., Hughes, C., and Koronakis, V. (2001). Protein export and drug efflux through bacterial channel-tunnels. Curr. Opin. Cell Biol. 13, 412-416.

Andersen, C., Koronakis, E., Bokma, E., Eswaran, J., Humphreys, D., Hughes, C., and Koronakis, V. (2002). Transition to the open state of the TolC periplasmic tunnel entrance. Proc. Natl. Acad. Sci. U.S.A. 99, 11103-11108.

Aono, R., Tsukagoshi, N., and Yamamoto, M. (1998). Involvement of outer membrane protein TolC, a possible member of the mar-sox regulon, in maintenance and improvement of organic solvent tolerance of Escherichia coli K-12. J. Bacteriol. 180, 938-944.

Barabote, R. D., Johnson, O. L., Zetina, E., San Francisco, S. K., Fralick, J. A., and San Francisco, M. J. (2003). Erwinia chrysanthemi tolC is involved in resistance to antimicrobial plant chemicals and is essential for phytopathogenesis. J. Bacteriol. 185, 5772-5778.

Barbosa, T. M., and Levy, S. B. (2000). Differential expression of over 60 chromosomal genes in Escherichia coli by constitutive expression of MarA. J. Bacteriol. 182, 3467-3474.

Bavro, V. N., Pietras, Z., Furnham, N., Perez-Cano, L., Fernandez-Recio, J., Pei, X. Y., Misra, R., and Luisi, B. (2008). Assembly and channel opening in a bacterial drug efflux machine. Mol. Cell 30, 114-121.

Bennion, D., Charlson, E. S., Coon, E., and Misra, R. (2010). Dissection of (B-barrel outer membrane protein assembly pathways through characterizing BamA POTRA 1 mutants of Escherichia coli. Mol. Microbiol. 77, 1153-1171.

Benz, R., Maier, E., and Gentschev, I. (1993). TolC of Escherichia coli functions as an outer membrane channel. Zentralbl. Bakteriol. 278, 187-196.

Bina, J. E., and Mekalanos, J. J. (2001). Vibrio cholerae tolC is required for bile resistance and colonization. Infect. Immun. 69, 4681-4685.

Bleuel, C., Grosse, C., Taudte, N., Scherer, J., Wesenberg, D., Krauss, G. J., Nies, D. H., and Grass, G. (2005). TolC is involved in enterobactin efflux across the outer membrane of Escherichia coli. J. Bacteriol. 187, 6701-6707.

Buckley, A. M., Webber, M. A., Cooles, S., Randall, L. P., La Ragione, R. M., Woodward, M. J., and Piddock, L. J. (2006). The AcrAB-TolC efflux system of Salmonella enterica serovar Typhimurium plays a role in pathogenesis. Cell. Microbiol. 8, 847-856.

Burgess, M. N., Bywater, R. J., Cowley, C. M., Mullan, N. A., and Newsome, P. M. (1978). Biological evaluation of a methanol-soluble, heat-stable Escherichia coli enterotoxin in infant mice, pigs, rabbits, and calves. Infect. Immun. 21, 526-531.

Bury-Moné, S., Nomane, Y., Reymond, N., Barbet, R., Jacquet, E., Imbeaud, S., Jacq, A., and Bouloc, P. (2009).

\section{ACKNOWLEDGMENTS}

This work was supported by National Institutes of Health Grant AI052293 to Helen I. Zgurskaya. Studies of TolC and its homologs in other species are overflowing. We apologize to our colleagues whose work we could not cite in this manuscript.

Global analysis of extracytoplasmic stress signaling in Escherichia coli. PLoS Genet. 5, e1000651. doi 10.1371/journal.pgen.1000651

Chuanchuen, R., Murata, T., Gotoh, N., and Schweizer, H. P. (2005). Substrate-dependent utilization of OprM or OpmH by the Pseudomonas aeruginosa MexJK efflux pump. Antimicrob. Agents Chemother. 49, 2133-2136.

Chubiz, L. M., and Rao, C. V. (2011). Role of the mar-sox-rob regulon in regulating outer membrane porin expression. J. Bacteriol. 193, 2252-2260.

Cosme, A. M., Becker, A., Santos, M. R., Sharypova, L. A., Santos, P. M., and Moreira, L. M. (2008). The outer membrane protein $\mathrm{TolC}$ from Sinorhizobium meliloti affects protein secretion, polysaccharide biosynthesis, antimicrobial resistance, and symbiosis. Mol. Plant Microbe Interact. 21, 947-957.

Deininger, K. N., Horikawa, A., Kitko, R. D., Tatsumi, R., Rosner, J. L., Wachi, M., and Slonczewski, J. L. (2011). A requirement of TolC and MDR efflux pumps for acid adaptation and GadAB induction in Escherichia coli. PLoS ONE 6, e18960. doi 10.1371/journal.pone. 0018960

Delcour, A. H. (2002). Structure and function of pore-forming betabarrels from bacteria. J. Mol. Microbiol. Biotechnol. 4, 1-10.

Delepelaire, P. (1998). Erwinia metalloprotease permease: aspects of secretion pathway and secretion functions. Meth. Enzymol. 292, 67-81.

Delepelaire, P. (2004). Type I secretion in Gram-negative bacteria. Biochim. Biophys. Acta 1694, 149-161.

Delgado, M. A., Solbiati, J. O., Chiuchiolo, M. J., Farias, R. N., and Salomon, R. A. (1999). Escherichia coli outer membrane protein $\mathrm{TolC}$ is involved in production of the peptide antibiotic microcin J25. J. Bacteriol. 181, 1968-1970.

Dhamdhere, G., Krishnamoorthy, G., and Zgurskaya, H. I. (2010). Interplay between drug efflux and antioxidants in Escherichia coli resistance to antibiotics. Antimicrob. Agents Chemother. 54, 5366-5368.

Dhamdhere, G., and Zgurskaya, H. I. (2010). Metabolic shutdown in Escherichia coli cells lacking the outer membrane channel TolC. Mol. Microbiol. 77, 743-754.

Dinh, T., Paulsen, I. T., and Saier, M. H. Jr. (1994). A family of extracytoplasmic proteins that allow transport of large molecules across the outer membranes of Gramnegative bacteria. J. Bacteriol. 176, 3825-3831.

Eguchi, Y., Oshima, T., Mori, H., Aono, R., Yamamoto, K., Ishihama, A., and Utsumi, R. (2003). Transcriptional regulation of drug efflux genes by EvgAS, a two-component system in Escherichia coli. Microbiology 149(Pt 10), 2819-2828.

Eswaran, J., Koronakis, E., Higgins, M. K., Hughes, C., and Koronakis, V. (2004). Three's company: component structures bring a closer view of tripartite drug efflux pumps. Curr. Opin. Struct. Biol. 14, 741-747.

Federici, L., Du, D., Walas, F., Matsumura, H., Fernandez-Recio, J., McKeegan, K. S., Borges-Walmsley, M. I., Luisi, B. F., and Walmsley, A. R. (2005). The crystal structure of the outer membrane protein $\mathrm{VceC}$ from the bacterial pathogen Vibrio cholerae at 1.8 A resolution. J. Biol. Chem. 280, 15307-15314.

Fenosa, A., Fuste, E., Ruiz, L., VeigaCrespo, P., Vinuesa, T., Guallar, V., Villa, T. G., and Vinas, M. (2009). Role of TolC in Klebsiella oxytoca resistance to antibiotics. J. Antimicrob. Chemother. 63, 668-674.

Ferhat, M., Atlan, D., Vianney, A., Lazzaroni, J. C., Doublet, P., and Gilbert, C. (2009). The TolC protein of Legionella pneumophila plays a major role in multi-drug resistance and the early steps of host invasion. PLoS ONE 4, e7732. doi: 10.1371/journal.pone.0007732

Foreman, D. T., Martinez, Y., Coombs, G., Torres, A., and Kupersztoch, Y. M. (1995). TolC and DsbA are needed for the secretion of STB, a heat-stable enterotoxin of Escherichia coli. Mol. Microbiol. 18, 237-245.

Foster, J. W. (2004). Escherichia coli acid resistance: tales of an amateur acidophile. Nat. Rev. Microbiol. 2, 898-907.

Fralick, J. A. (1996). Evidence that TolC is required for functioning of the Mar/AcrAB efflux pump of Escherichia coli. J. Bacteriol. 178 5803-5805. 
Fralick, J. A., and Burns-Keliher, L. L. (1994). Additive effect of tolC and rfa mutations on the hydrophobic barrier of the outer membrane of Escherichia coli K-12. J. Bacteriol. 176, 6404-6406.

Franke, S., Grass, G., Rensing, C., and Nies, D. H. (2003). Molecular analysis of the copper-transporting efflux system CusCFBA of Escherichia coli. J. Bacteriol. 185, 3804-3812.

Ge, Q., Yamada, Y., and Zgurskaya, H. (2009). The C-terminal domain of AcrA is essential for the assembly and function of the multidrug efflux pump AcrAB-TolC. J. Bacteriol. 191, 4365-4371.

Gil, H., Platz, G. J., Forestal, C. A., Monfett, M., Bakshi, C. S., Sellati, T. J., Furie, M. B., Benach, J. L., and Thanassi, D. G. (2006). Deletion of TolC orthologs in Francisella tularensis identifies roles in multidrug resistance and virulence. Proc. Natl. Acad. Sci. U.S.A. 103, 12897-12902.

Groisman, E. A. (2001). The pleiotropic two-component regulatory system PhoP-PhoQ. J. Bacteriol. 183, 1835-1842.

Hagan, C. L., Silhavy, T. J., and Kahne, D. (2011). beta-Barrel membrane protein assembly by the Bam complex. Annu. Rev. Biochem. 80, 189-210.

Hantke, K., Winkler, K., and Schultz, J. E. (2011). Escherichia coli exports cyclic AMP via TolC. J. Bacteriol. 193 , 1086-1089.

Hatfaludi, T., Al-Hasani, K., Dunstone, M., Boyce, J., and Adler, B. (2008). Characterization of TolC efflux pump proteins from Pasteurella multocida. Antimicrob. Agents Chemother. 52, 4166-4171.

Horiyama, T., Yamaguchi, A., and Nishino, K. (2010). TolC dependency of multidrug efflux systems in Salmonella enterica serovar Typhimurium. J. Antimicrob. Chemother. 65, 1372-1376.

Hwang, J., Zhong, X., and Tai, P. C. (1997). Interactions of dedicated export membrane proteins of the colicin $\mathrm{V}$ secretion system: CvaA, a member of the membrane fusion protein family, interacts with $\mathrm{CvaB}$ and TolC. J. Bacteriol. 179, 6264-6270.

Imlay, J. A. (2008). Cellular defenses against superoxide and hydrogen peroxide. Annu. Rev. Biochem. 77, 755-776.

Imuta, N., Nishi, J., Tokuda, K., Fujiyama, R., Manago, K., Iwashita, M., Sarantuya, J., and Kawano, Y. (2008). The Escherichia coli efflux pump TolC promotes aggregation of enteroaggregative E. coli 042. Infect. Immun. 76, 1247-1256.

Janganan, T. K., Bavro, V. N., Zhang, L., Matak-Vinkovic, D., Barrera, N. P., Venien-Bryan, C., Robinson, C. V., Borges-Walmsley, M. I., and Walmsley, A. R. (2011). Evidence for the assembly of a bacterial tripartite multidrug pump with a stoichiometry of 3:6:3. J. Biol. Chem. 286, 26900-26912.

Jo, J. T., Brinkman, F. S., and Hancock, R. E. (2003). Aminoglycoside efflux in Pseudomonas aeruginosa: involvement of novel outer membrane proteins. Antimicrob. Agents Chemother. 47, 1101-1111.

Johnson, J. M., and Church, G. M. (1999). Alignment and structure prediction of divergent protein families: periplasmic and outer membrane proteins of bacterial efflux pumps. J. Mol. Biol. 287, 695-715.

Kim, E.-H., Nies, D. H., McEvoy, M. M., and Rensing, C. (2011). Switch or funnel: how RND-type transport systems control periplasmic metal homeostasis. J. Bacteriol. 193, 2381-2387.

Kohanski, M. A., Dwyer, D. J., Hayete, B., Lawrence, C. A., and Collins, J. J. (2007). A common mechanism of cellular death induced by bactericidal antibiotics. Cell 130, 797-810.

Koronakis, V. (2003). TolC - the bacterial exit duct for proteins and drugs. FEBS Lett. 555, 66-71.

Koronakis, V., Sharff, A., Koronakis, E., Luisi, B., and Hughes, C. (2000). Crystal structure of the bacterial membrane protein TolC central to multidrug efflux and protein export. Nature 405, 914-919.

Krishnamoorthy, G., Tikhonova, E. B., and Zgurskaya, H. I. (2008). Fitting periplasmic membrane fusion proteins to inner membrane transporters: mutations that enable Escherichia coli AcrA to function with Pseudomonas aeruginosa MexB. J. Bacteriol. 190, 691-698.

Kulathila, R., Indic, M., and van den Berg, B. (2011). Crystal structure of Escherichia coli $\mathrm{CusC}$, the outer membrane component of a heavy metal efflux pump. PLoS ONE 6, e15610. doi: 10.1371/journal.pone. 0015610

Leblanc, S. K. D., Oates, C. W., and Raivio, T. L. (2011). Characterization of the induction and cellular role of the BaeSR twocomponent envelope stress response of Escherichia coli. J. Bacteriol. 193, 3367-3375.

Letoffe, S., Ghigo, J. M., and Wandersman, C. (1993). Identification of two components of the Serratia marcescens metalloprotease transporter: protease SM secretion in Escherichia coli is TolC dependent. J. Bacteriol. 175, 7321-7328.

Letoffe, S., Ghigo, J. M., and Wandersman, C. (1994). Secretion of the Serratia marcescens HasA protein by an ABC transporter. J. Bacteriol. 176, 5372-5377.

Li, X. Z., Nikaido, H., and Poole, K. (1995). Role of mexA-mexB-oprM in antibiotic efflux in Pseudomonas aeruginosa. Antimicrob. Agents Chemother. 39, 1948-1953.

Lobedanz, S., Bokma, E., Symmons, M. F., Koronakis, E., Hughes, C., and Koronakis, V. (2007). A periplasmic coiled-coil interface underlying TolC recruitment and the assembly of bacterial drug efflux pumps. Proc. Natl. Acad. Sci. U.S.A. 104 4612-4617.

Martin, R. G., and Rosner, J. L. (2002). Genomics of the marA/soxS/rob regulon of Escherichia coli: identification of directly activated promoters by application of molecular genetics and informatics to microarray data. Mol. Microbiol. 44, 1611-1624.

Masi, M., Duret, G., Delcour, A. H. and Misra, R. (2009). Folding and trimerization of signal sequence-less mature TolC in the cytoplasm of Escherichia coli. Microbiology 155(Pt 6), 1847-1857.

Masuda, N., and Church, G. M. (2003). Regulatory network of acid resistance genes in Escherichia coli. Mol. Microbiol. 48, 699-712.

Misra, R., and Bavro, V. N. (2009). Assembly and transport mechanism of tripartite drug efflux systems. Biochim. Biophys. Acta 1794, 817-825.

Misra, R., and Reeves, P. R. (1987) Role of micF in the tolC-mediated regulation of OmpF, a major outer membrane protein of Escherichia coli K-12. J. Bacteriol. 169, 4722-4730.

Modali, S. D., and Zgurskaya, H. I. (2011). The periplasmic membrane proximal domain of MacA acts as a switch in stimulation of ATP hydrolysis by MacB transporter. Mol. Microbiol. 81, 937-951.

Morona, R., Manning, P. A., and Reeves, P. (1983). Identification and characterization of the TolC protein, an outer membrane protein from Escherichia coli. J. Bacteriol. 153, 693-699.

Morona, R., and Reeves, P. (1981). Molecular cloning of the tolC locus of Escherichia coli K-12 with the use of transposon Tn10. Mol. Gen. Genet. 184, 430-433.
Morona, R., and Reeves, P. (1982). The tolC locus of Escherichia coli affects the expression of three major outer membrane proteins. J. Bacteriol. 150, 1016-1023.

Murakami, S., Nakashima, R., Yamashita, E., and Yamaguchi, A. (2002). Crystal structure of bacterial multidrug efflux transporter Acr. Nature 419, 587-593.

Newton, S. M., Trinh, V., Pi, H., and Klebba, P. E. (2010). Direct measurements of the outer membrane stage of ferric enterobactin transport: post uptake binding. J. Biol. Chem. 285, 17488-17497.

Nichols, R. J., Sen, S., Choo, Y. J., Beltrao, P., Zietek, M., Chaba, R., Lee, S., Kazmierczak, K. M., Lee, K. J., Wong, A., Shales, M., Lovett, S., Winkler, M. E., Krogan, N. J., Typas, A., and Gross, C. A. (2011). Phenotypic landscape of a bacterial cell. Cell 144, 143-156.

Nikaido, H. (2009). Multidrug resistance in bacteria. Annu. Rev. Biochem. 78, 119-146.

Nikaido, H., and Takatsuka, Y. (2009). Mechanisms of RND multidrug efflux pumps. Biochim. Biophys. Acta 1794, 769-781.

Nishino, K., Honda, T., and Yamaguchi, A. (2005). Genome-wide analyses of Escherichia coli gene expression responsive to the BaeSR two-component regulatory system. J. Bacteriol. 187, 1763-1772.

Nishino, K., Latifi, T., and Groisman, E. A. (2006). Virulence and drug resistance roles of multidrug efflux systems of Salmonella enterica serovar Typhimurium. Mol. Microbiol. 59, 126-141.

Nishino, K., and Yamaguchi, A. (2001). Analysis of a complete library of putative drug transporter genes in Escherichia coli. J. Bacteriol. 183, 5803-5812.

Okamoto, K., and Takahara, M. (1990). Synthesis of Escherichia coli heatstable enterotoxin STp as a prepro form and role of the pro sequence in secretion. J. Bacteriol. 172, 5260-5265.

Park, S., and Imlay, J. A. (2003). High levels of intracellular cysteine promote oxidative DNA damage by driving the fenton reaction. J. Bacteriol. 185, 1942-1950.

Paulsen, I. T., Park, J. H., Choi, P. S., and Saier, M. H. Jr. (1997) A family of Gram-negative bacterial outer membrane factors that function in the export of proteins, carbohydrates, drugs and heavy metals from Gram-negative bacteria. FEMS Microbiol. Lett. 156, $1-8$. 
Pei, X. Y., Hinchliffe, P., Symmons, M. F., Koronakis, E., Benz, R., Hughes, C., and Koronakis, V. (2011). Structures of sequential open states in a symmetrical opening transition of the TolC exit duct. Proc. Natl. Acad. Sci. U.S.A. 108, 2112-2117.

Phan, G., Benabdelhak, H., Lascombe, M. B., Benas, P., Rety, S., Picard, M., Ducruix, A., Etchebest, C. and Broutin, I. (2010). Structural and dynamical insights into the opening mechanism of $P$. aeruginosa OprM channel. Structure 18, 507-517.

Piddock, L. J. (2006). Multidrugresistance efflux pumps - not just for resistance. Nat. Rev. Microbiol. 4, 629-636.

Poole, K. (2004). Efflux-mediated multiresistance in Gram-negative bacteria. Clin. Microbiol. Infect. 10, $12-26$

Pos, K. M. (2009). Drug transport mechanism of the AcrB efflux pump. Biochim. Biophys. Acta 1794, 782-793.

Posadas, D. M., Martin, F. A., Sabio y Garcia, J. V., Spera, J. M., Delpino, M. V., Baldi, P., Campos, E., Cravero, S. L., and Zorreguieta, A. (2007). The TolC homologue of Brucella suis is involved in resistance to antimicrobial compounds and virulence. Infect. Immun. 75, 379-389.

Randall, L. P., and Woodward, M. J. (2002). The multiple antibiotic resistance (mar) locus and its significance. Res. Vet. Sci. 72, 87-93.

Reddy, J. D., Reddy, S. L., Hopkins, D. L., and Gabriel, D. W. (2007). TolC is required for pathogenicity of Xylella fastidiosa in Vitis vinifera grapevines. Mol. Plant Microbe Interact. 20, 403-410.

Rosner, J. L., and Martin, R. G. (2009). An excretory function for the Escherichia coli outer membrane pore TolC: upregulation of marA and soxS transcription and Rob activity due to metabolites accumulated in tolC mutants. J. Bacteriol. 191, 5283-5292.

Stegmeier, J. F., Polleichtner, G., Brandes, N., Hotz, C., and Andersen, C. (2006). Importance of the adaptor (membrane fusion) protein hairpin domain for the functionality of multidrug efflux pumps. Biochemistry 45, 10303-10312.

Stone, B. J., and Miller, V. L. (1995). Salmonella enteritidis has a homologue of tolC that is required for virulence in BALB/c mice. Mol. Microbiol. 17, 701-712.
Su, C.-C., Long, F., Zimmermann, M. T., Rajashankar, K. R., Jernigan, R. L., and Yu, E. W. (2011) Crystal structure of the CusBA heavy-metal efflux complex of Escherichia coli. Nature 470, 558-562.

Sulavik, M. C., Houseweart, C., Cramer, C., Jiwani, N., Murgolo, N., Greene, J., DiDomenico, B., Shaw, K. J., Miller, G. H., Hare, R., and Shimer, G. (2001). Antibiotic susceptibility profiles of Escherichia coli strains lacking multidrug efflux pump genes. Antimicrob. Agents Chemother. 45, 1126-1136.

Swick, M. C., Morgan-Linnell, S. K., Carlson, K. M., and Zechiedrich, L. (2011). Expression of multidrug efflux pump genes acrAB-tolC, mdfA, and norE in Escherichia coli clinical isolates as a function of fluoroquinolone and multidrug resistance. Antimicrob. Agents Chemother. 55, 921-924.

Symmons, M. F., Bokma, E., Koronakis, E., Hughes, C., and Koronakis, V. (2009). The assembled structure of a complete tripartite bacterial multidrug efflux pump. Proc. Natl. Acad. Sci. U.S.A. 106, 7173-7178.

Tamura, N., Murakami, S., Oyama, Y., Ishiguro, M., and Yamaguchi, A. (2005). Direct interaction of multidrug efflux transporter AcrB and outer membrane channel TolC detected via site-directed disulfide cross-linking. Biochemistry 44, 11115-11121.

Tatsumi, R., and Wachi, M. (2008). TolC-dependent exclusion of porphyrins in Escherichia coli. J. Bacteriol. 190, 6228-6233.

Thanabalu, T., Koronakis, E., Hughes, C., and Koronakis, V. (1998). Substrate-induced assembly of a contiguous channel for protein export from E. coli: reversible bridging of an inner-membrane translocase to an outer membrane exit pore. EMBO J. 17, 6487-6496.

Tikhonova, E. B., Dastidar, V., Rybenkov, V. V., and Zgurskaya, H. I. (2009). Kinetic control of TolC recruitment by multidrug efflux complexes. Proc. Natl. Acad. Sci. U.S.A. 106, 16416-16421.

Tikhonova, E. B., Yamada, Y., and Zgurskaya, H. I. (2011). Sequential mechanism of assembly of multidrug efflux pump AcrAB-TolC. Chem. Biol. 18, 454-463.

Tikhonova, E. B., and Zgurskaya, H. I. (2004). AcrA, AcrB, and
TolC of Escherichia coli form a stable intermembrane multidrug efflux complex. J. Biol. Chem. 279, 32116-32124.

Trent, M. S., Worsham, L. M., and ErnstFonberg, M. L. (1998). The biochemistry of hemolysin toxin activation: characterization of $\mathrm{HlyC}$, an internal protein acyltransferase. Biochemistry 37, 4644-4652.

Trepod, C. M., and Mott, J. E. (2004) Identification of the Haemophilus influenzae tolC gene by susceptibility profiles of insertionally inactivated efflux pump mutants. Antimicrob. Agents Chemother. 48, 1416-1418.

Vakharia, H., German, G. J., and Misra, R. (2001). Isolation and characterization of Escherichia coli tolC mutants defective in secreting enzymatically active alpha-hemolysin. $J$. Bacteriol. 183, 6908-6916.

van Amsterdam, K., Bart, A., and van der Ende, A. (2005). A Helicobacter pylori TolC efflux pump confers resistance to metronidazole. Antimicrob. Agents Chemother. 49, 1477-1482.

Wandersman, C., and Delepelaire, P. (1990). TolC, an Escherichia coli outer membrane protein required for hemolysin secretion. Proc. Natl. Acad. Sci. U.S.A. 87, 4776-4780.

Webber, M. A., Bailey, A. M., Blair, J. M. Morgan, E., Stevens, M. P., Hinton, J. C., Ivens, A., Wain, J., and Piddock, L. J. (2009). The global consequence of disruption of the AcrAB-TolC efflux pump in Salmonella enterica includes reduced expression of SPI- 1 and other attributes required to infect the host. J. Bacteriol. 191 4276-4285.

Werner, J., Augustus, A. M., and Misra, R. (2003). Assembly of TolC, structurally unique and multifunctional outer membrane protein of Escherichia coli K-12. J. Bacteriol. 185, 6540-6547.

Wiriyathanawudhiwong, N., Ohtsu, I. Li, Z. D., Mori, H., and Takagi, H. (2009). The outer membrane TolC is involved in cysteine tolerance and overproduction in Escherichia coli. Appl. Microbiol. Biotechnol. 81, 903-913.

Xu, Y., Lee, M., Moeller, A., Song, S., Yoon, B.-Y., Kim, H.-M., Jun, S.Y., Lee, K., and Ha, N.-C. (2011a). Funnel-like hexameric assembly of the periplasmic adapter protein in the tripartite multidrug efflux pump in Gram-negative bacteria. J. Biol. Chem. 286, 17910-17920.

Xu, Y., Song, S., Moeller, A., Kim, N., Piao, S., Sim, S. H., Kang, M., Yu, W.,
Cho, H. S., Chang, I., Lee, K., and Ha, N. C. (2011b). Functional implications of an intermeshing cogwheellike interaction between TolC and $\mathrm{MacA}$ in the action of macrolidespecific efflux pump MacAB-TolC. J. Biol. Chem. 286, 13541-13549.

Xu, Y., Sim, S. H., Nam, K. H., Jin, X. L., Kim, H. M., Hwang, K. Y., Lee, K., and Ha, N. C. (2009). Crystal structure of the periplasmic region of $\mathrm{MacB}$, a noncanonic $\mathrm{ABC}$ transporter. Biochemistry 48, 5218-5225.

Xu, Y., Sim, S. H., Song, S., Piao, S., Kim, H. M., Jin, X. L., Lee, K., and Ha, N. C. (2010). The tip region of the MacA alpha-hairpin is important for the binding to TolC to the Escherichia coli MacAB-TolC pump. Biochem. Biophys. Res. Commun. 394, 962-965.

Yamanaka, H., Fuke, Y., Hitotsubashi, S., Fujii, Y., and Okamoto, K. (1993). Functional properties of pro region of Escherichia coli heat-stable enterotoxin. Microbiol. Immunol.37, 195-205.

Yamanaka, H., Kobayashi, H., Takahashi, E., and Okamoto, K. (2008) $\mathrm{MacAB}$ is involved in the secretion of Escherichia coli heat-stable enterotoxin II. J. Bacteriol. 190, 7693-7698

Yamanaka, H., Nomura, T., Fujii, Y., and Okamoto, K. (1998). Need for TolC, an Escherichia coli outer membrane protein, in the secretion of heat-stable enterotoxin I across the outer membrane. Microb. Pathog. 25, 111-120.

Yohannes, E., Barnhart, D. M., and Slonczewski, J. L. (2004). pH-dependent catabolic protein expression during anaerobic growth of Escherichia coli K-12. J. Bacteriol. 186, 192-199.

Zgurskaya, H. I. (2009). Multicomponent drug efflux complexes: architecture and mechanism of assembly. Future Microbiol. 4, 919-932.

Zgurskaya, H. I., Yamada, Y., Tikhonova, E. B., Ge, Q., and Krishnamoorthy, G. (2009). Structural and functional diversity of bacterial membrane fusion proteins. Biochim. Biophys. Acta 1794, 794-807.

Zhang, A., Rosner, J. L., and Martin, R. G. (2008). Transcriptional activation by MarA, SoxS and Rob of two tolC promoters using one binding site: a complex promoter configuration for tolC in Escherichia coli. Mol. Microbiol. 69, 1450-1455.

Zufferey, R., Hennecke, H., and Thony-Meyer, L. (1997). Heme $\mathrm{C}$ incorporation into the c-type 
cytochromes FixO and FixP is essential for assembly of the Bradyrhizobium japonicum cbb3-type oxidase. FEBS Lett. 412, 75-78.

Conflict of Interest Statement: The authors declare that the research was conducted in the absence of any commercial or financial relationships that could be construed as a potential conflict of interest.

Received: 26 July 2011; paper pending published: 17 August 2011; accepted: 25 August 2011; published online: 16 September 2011.

Citation: Zgurskaya HI, Krishnamoorthy G, Ntreh A and Lu S (2011)
Mechanism and function of the outer membrane channel TolC in multidrug resistance and physiology of enterobacteria. Front. Microbio. 2:189. doi: 10.3389/fmicb.2011.00189

This article was submitted to Frontiers in Antimicrobials, Resistance and Chemotherapy, a specialty of Frontiers in Microbiology.
Copyright (ㅇ 2011 Zgurskaya, Krishnamoorthy, Ntreh and Lu. This is an open-access article subject to a nonexclusive license between the authors and Frontiers Media SA, which permits use, distribution and reproduction in other forums, provided the original authors and source are credited and other Frontiers conditions are complied with. 


\section{APPENDIX}

Table A1 | Predicted functional partners of TolC.

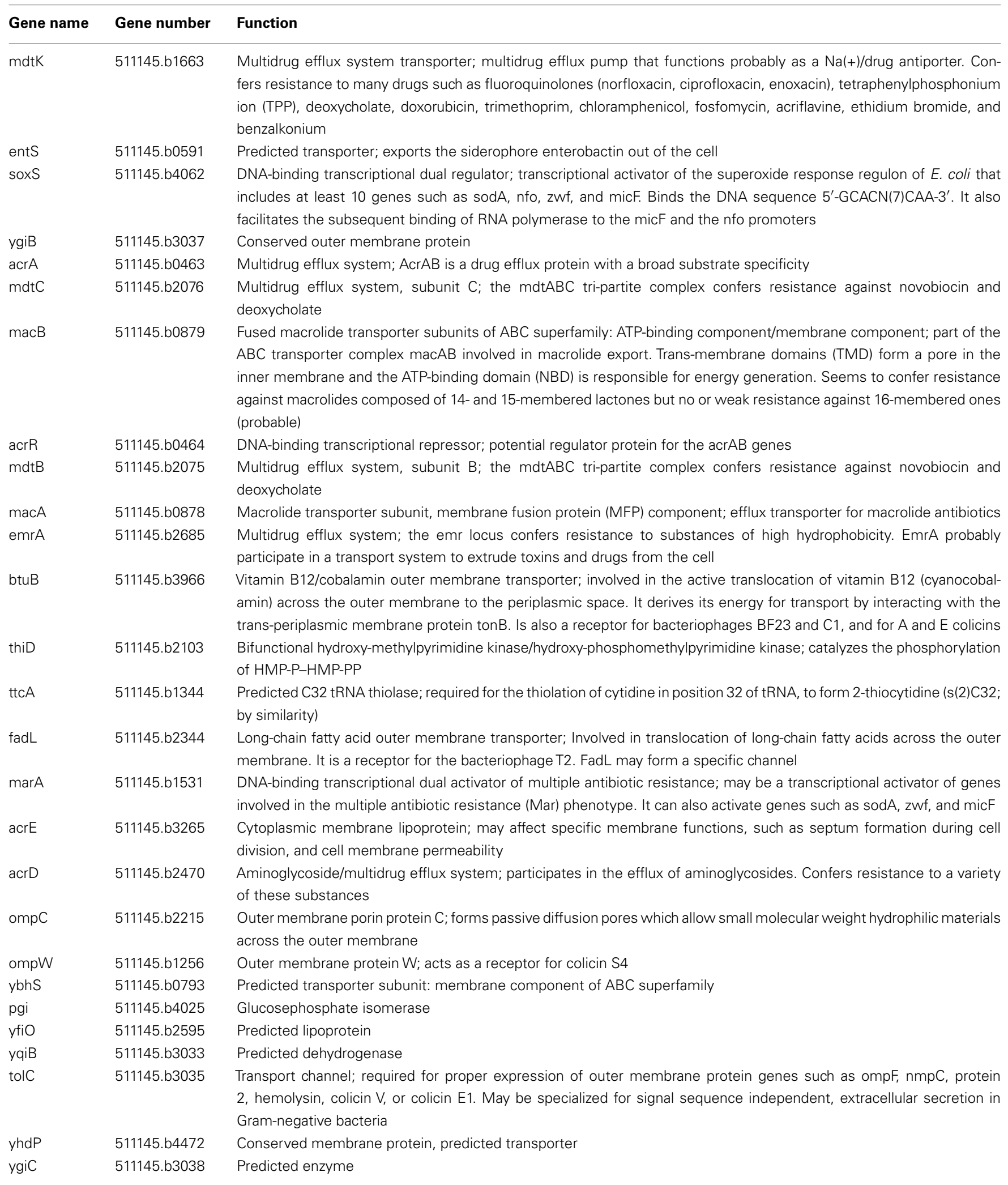


Table A1 | Continued

\begin{tabular}{|c|c|c|}
\hline Gene name & Gene number & Function \\
\hline $\mathrm{rob}$ & $511145 . b 4396$ & $\begin{array}{l}\text { DNA-binding transcriptional activator; binds to the right arm of the replication origin oriC of the chromosome. Rob binding } \\
\text { may influence the formation of the nucleoprotein structure, required for oriC function in the initiation of replication }\end{array}$ \\
\hline emrK & $511145 . b 2368$ & EmrKY-TolC multidrug resistance efflux pump, membrane fusion protein component \\
\hline ompT & $511145 . b 0565$ & $\begin{array}{l}\text { DLP12 prophage; outer membrane protease VII (outer membrane protein 3b); protease that can cleave T7 RNA poly- } \\
\text { merase, ferric-enterobactin receptor protein (FEP), antimicrobial peptide protamine, and other proteins. This protease } \\
\text { has a specificity for paired basic residues }\end{array}$ \\
\hline yqiA & $511145 . b 3031$ & Predicted esterase; displays esterase activity toward palmitoyl-CoA and pNP-butyrate \\
\hline thiC & 511145.b3994 & $\begin{array}{l}\text { Thiamin (pyrimidine moiety) biosynthesis protein; required for the synthesis of the hydroxymethylpyrimidine (HMP) } \\
\text { moiety of thiamine (4-amino-2-methyl-5-hydroxymethylpyrimidine) }\end{array}$ \\
\hline secE & $511145 . b 3981$ & Preprotein translocase membrane subunit; essential for protein export \\
\hline emrB & $511145 . b 2686$ & Multidrug efflux system protein; translocase that confers resistance to substances of high hydrophobicity \\
\hline ompF & 511145.b0929 & $\begin{array}{l}\text { Outer membrane porin 1a }(\mathrm{Ia} ; \mathrm{b} ; \mathrm{F}) ; \mathrm{OmpF} \text { is a porin that forms passive diffusion pores which allow small molecular } \\
\text { weight hydrophilic materials across the outer membrane. It is also a receptor for the bacteriophage T2 }\end{array}$ \\
\hline parE & $511145 . b 3030$ & $\begin{array}{l}\text { DNA topoisomerase IV, subunit B; topoisomerase IV is essential for chromosome segregation. It has relaxation of } \\
\text { supercoiled DNA activity. Performs the decatenation events required during the replication of a circular DNA molecule }\end{array}$ \\
\hline emrX & $511145 . b 2367$ & Predicted multidrug efflux system \\
\hline $\mathrm{pcm}$ & $511145 . b 2743$ & $\begin{array}{l}\text { I-isoaspartate protein carboxylmethyltransferase type II; catalyzes the methyl esterification of I-isoaspartyl residues in } \\
\text { peptides and proteins that result from spontaneous decomposition of normal I-aspartyl and I-asparaginyl residues. It } \\
\text { plays a role in the repair and/or degradation of damaged proteins. This enzyme does not act on d-aspartyl residues }\end{array}$ \\
\hline mdtF & $511145 . b 3514$ & $\begin{array}{l}\text { Multidrug transporter, RpoS-dependent; Part of a multidrug resistance efflux system that confers resistance to com- } \\
\text { pounds such as rhodamine } 6 G \text {, erythromycin, doxorubicin, ethidium bromide, TPP, SDS, deoxycholate, crystal violet, } \\
\text { and benzalkonium }\end{array}$ \\
\hline mdtA & $511145 . b 2074$ & $\begin{array}{l}\text { Multidrug efflux system, subunit } A \text {; the mdtABC tri-partite complex confers resistance against novobiocin and } \\
\text { deoxycholate }\end{array}$ \\
\hline mdtE & $511145 . b 3513$ & $\begin{array}{l}\text { Multidrug resistance efflux transporter; part of a multidrug resistance efflux system that confers resistance to com- } \\
\text { pounds such as rhodamine } 6 G \text {, erythromycin, doxorubicin, ethidium bromide, TPP, SDS, deoxycholate, crystal violet, } \\
\text { and benzalkonium }\end{array}$ \\
\hline icc & $511145 . b 3032$ & $3^{\prime}, 5^{\prime}$ cAMP phosphodiesterase (EC:3.1.4.17); Affects the expression of the lacZ gene \\
\hline tolB & $511145 . b 0740$ & $\begin{array}{l}\text { Periplasmic protein; Involved in the tonB-independent uptake of group A colicins (colicins A, E1, E2, E3, and K). Necessary } \\
\text { for the colicins to reach their respective targets after initial binding to the bacteria }\end{array}$ \\
\hline acrF & $511145 . b 3266$ & Multidrug efflux system protein; involved in cell envelope formation. Is produced in extremely low amounts \\
\hline $\mathrm{yfgC}$ & $511145 . b 2494$ & Predicted peptidase \\
\hline yaeT & $511145 \cdot b 0177$ & $\begin{array}{l}\text { Conserved protein; involved in the assembly of outer membrane proteins. Does not play a direct role in the export of } \\
\text { outer membrane lipids }\end{array}$ \\
\hline phoP & $511145 . b 1130$ & $\begin{array}{l}\text { DNA-binding response regulator in two-component regulatory system with PhoQ; Member of the two-component } \\
\text { regulatory system phoQ/phoP involved in adaptation to low } \mathrm{Mg}(2+) \text { environments and the control of acid resistance } \\
\text { genes. Mediates magnesium influx to the cytosol by activation of mgtA. Promotes expression of the two-component } \\
\text { regulatory system rstA/rstB and transcription of the hemL, } \mathrm{mgrB} \text {, nagA, slyB, vboR, and yrbL genes }\end{array}$ \\
\hline acrB & $511145 . b 0462$ & Multidrug efflux system protein; AcrAB is a drug efflux protein with a broad substrate specificity \\
\hline ecfM & 511145.b3096 & Conserved protein \\
\hline$n f n B$ & 511145.b0578 & $\begin{array}{l}\text { Dihydropteridine reductase, } \mathrm{NAD}(\mathrm{P}) \mathrm{H} \text {-dependent, oxygen-insensitive; Reduction of a variety of nitroaromatic com- } \\
\text { pounds using } \mathrm{NADH} \text { (and to lesser extent } \mathrm{NADPH} \text { ) as source of reducing equivalents; two electrons are transferred. } \\
\text { Capable of reducing nitrofurazone, quinones, and the anti-tumor agent CB1954 [5-(aziridin-1-yl)-2,4-dinitrobenzamide]. } \\
\text { The reduction of } \mathrm{CB} 1954 \text { results in the generation of cytotoxic species }\end{array}$ \\
\hline nudF & 511145.b3034 & $\begin{array}{l}\text { ADP-ribose pyrophosphatase; acts on ADP-mannose; and ADP-glucose as well as ADP-ribose. Prevents glycogen } \\
\text { biosynthesis. The reaction catalyzed by this enzyme is a limiting step of the gluconeogenic process }\end{array}$ \\
\hline
\end{tabular}

